\title{
DESINFECÇÃO E ESTERILIZAÇÃO EM SERVIÇOS AMBULATORIAIS DE SAÚDE DO TRABALHADOR
}

\author{
Aline Mara Jacoby ${ }^{1}$, Karen Cristina Jung Rech ${ }^{2}$, Rosana Amora Ascari ${ }^{3}$
}

\begin{abstract}
RESUMO: Este estudo teve por objetivo conhecer o processo de desinfecção e esterilização de materiais em unidades ambulatoriais de saúde do trabalhador, dos estados de Santa Catarina, Rio Grande do Sul e Mato Grosso do Sul. Trata-se de estudo de casorealizado em 15 unidades de atendimento ambulatorial de saúde do trabalhador, no período de junho a setembro de 2013, com questionário aplicado individualmente aos profissionais atuantes na área de esterilização na sede da empresa. Todas as unidades utilizam autoclave como método de esterilização, realizada nas salas de procedimentos médico-odontológicos. Foram identificados: falta padronização de rotulagem dos produtos, testes de validação e registros das esterilizações realizadas. A qualidade e segurança do processo de esterilização estão comprometidas nas unidades pesquisadas, necessitando de intervenção na estrutura física e redefinição dos processos de monitoramento e registro das esterilizações para melhoria das condições sanitárias e de segurança do trabalhador.
\end{abstract}

DESCRITORES: Esterilização; Enfermagem do Trabalho; Saúde do Trabalhador; Riscos Ocupacionais.

\section{DISINFECTION AND STERILIZATION IN OUTPATIENT OCCUPATIONAL HEALTH SERVICES}

\begin{abstract}
This study aimed to investigate the process of disinfection and sterilization of materials in outpatient occupational health units, in the Brazilian states of Santa Catarina, Rio Grande do Sul, and Mato Grosso do Sul. It is a case study undertaken in 15 outpatient occupational health units, in June - September 2013, with a questionnaire applied individually to the professionals working in the area of sterilization in the company's head office.All the units use the autoclave as the method of sterilization, undertaken in the medicaldental procedure rooms. The following were identified: there is a lack of standardization of products' labeling, validation tests and records of the sterilizations undertaken. The quality and safety of the sterilization process are compromised in the units studied, and require intervention in the physical structure and redefinition of the processes of monitoring and recording the sterilizations for improvement of the health conditions, and of the worker's safety.
\end{abstract}

DESCRIPTORS: Sterilization; Occupational Nursing; Occupational Health; Occupational risks.

\section{DESINFECCIÓN Y ESTERILIZACIÓN EN SERVICIOS DE AMBULATORIOS DE SALUD DEL TRABAJADOR}

RESUMEN: Este estudio tuvo el objetivo de conocer el proceso de desinfección y esterilización de materiales en unidades de ambulatorios de salud del trabajador, de los estados de Santa Catarina, Rio Grande do Sul y Mato Grosso do Sul. Es un estudio de caso realizado en 15 unidades de atendimiento de ambulatorio de salud del trabajador, en el periodo de junio a septiembre de 2013, con cuestionario aplicado individualmente a los profesionales actuantes en el área de esterilización en la sede de la empresa. Todas las unidades utilizan autoclave como método de esterilización, la cual es realizada en los locales de procedimientos médicoodontológicos. Se identificaron: falta de estandarización de etiquetaje de los productos, testes de validación y registros de las esterilizaciones realizadas. La cualidad y seguridad del proceso de esterilización estan comprometidas en las unidades investigadas, necesitándose de intervención en la estructura física y redefinición de los procesos de monitoreo y registro de las esterilizaciones para mejorar las condiciones sanitarias y de seguridad del trabajador.

DESCRIPTORES: Esterilización; Enfermería del Trabajo; Salud del Trabajador; Riesgos Ocupacionales.

1Enfermeira. Universidade do Estado de Santa Catarina, Chapecó, SC, Brasil.

2Enfermeira. Especialista em Enfermagem do Trabalho. Hospital Regional do Oeste. Chapecó, SC, Brasil.

${ }^{3}$ Enfermeira. Doutoranda em Enfermagem. Docente da Universidade do Estado de Santa Catarina.Chapecó, SC, Brasil. 


\section{- INTRODUÇÃO}

A esterilização é um processo que elimina por completo os micro-organismos, sendo importante que os profissionais de enfermagem conheçam todos os procedimentos, tais como a limpeza e manuseio, seleção de embalagem, empacotamento, método de esterilização, armazenamento dos produtos para saúde, testes e registros para a validação do processo de esterilização. Todos os profissionais envolvidos neste processo devem estar preparados para desenvolver estes procedimentos de forma segura. Assim, os serviços de saúde devem dispor de profissionais, artigos e um conjunto de medidas seguras para oferecer cuidado adequado, sem risco algum ao usuário e ao profissional dos serviços de saúde ${ }^{(1-3)}$.

Estudos sinalizam fragilidades nos processos deesterilização de materiais, por vezes destoando da legislação brasileira e das recomendações mínimas de segurança e validação da esterilização, colocando em risco a segurança tanto dos trabalhadores como dos indivíduos que utilizam esses serviços $^{(4-6)}$. Pesquisa desenvolvida com 18 trabalhadores de enfermagem em um hospital público de Porto Alegre, em 2011, identificou que alguns participantes não têm conhecimento adequado sobre todas as etapas que permeiam o processo de esterilização de produtos para saúde ${ }^{(7)}$.

A desinfecção e a esterilização são processos que podem eliminar ou reduzir de forma significativa os riscos de infecção ${ }^{(2,6)}$. Considerando que o centro de material e esterilização (CME) é composto pelas áreas suja, limpa e estéril ${ }^{(5,7-8)}$, o profissional de saúde possui grande responsabilidade, uma vez que deve distinguir a área de atuação e o risco potencial de transmissão de infecção por meio de instrumentos e materiais utilizados.Para isso, são fundamentais ações como limpeza, secagem, preparo, esterilização e estocagem adequada dos materiais ${ }^{(4-5,8-9)}$.

Segundo as normas internacionais de segurança, a equipe que atua nos processos de esterilizaçãoé obrigada a fazer uso dos equipamentos de proteção individual (EPIs) ${ }^{(8-9)}$, os quais devem estar sempre disponíveis à equipe, tais como aventais, máscaras faciais, luvas, botas, toucas, entre outros, diminuindo, assim, a probabilidade de contaminação ${ }^{(1,10)}$.

De acordo com a legislação brasileira, todas as unidades que utilizam produtos para saúde necessitam de um controle rigoroso ${ }^{(11)} \mathrm{com}$ finalidade de não comprometer o bem-estar dos indivíduos assistidos nos serviços de atenção à saúde ${ }^{(2)}$.

Nesse sentido, estudo aponta os avanços na política nacional de saúde do trabalhador e reforça a importância da educação em serviço para a minimização de doenças relacionadas ao trabalho, além do compromisso de gestores, trabalhadores e empregadores com a qualidade do trabalho e com a valorização dos trabalhadores ${ }^{(12)}$.

Com base nesse contexto, questiona-se: como é o processo de desinfecção e esterilização em serviços ambulatoriais de saúde do trabalhador? A partir deste questionamento é que se propôs um estudo para conhecer o processo de desinfecção e esterilização em serviços ambulatoriais de saúde do trabalhador em uma empresa do ramo alimentíciocom filiais nos estados de Santa Catarina, Rio Grande do Sul e Mato Grosso do Sul.

Considerandoo potencial de contaminaçãoexistente em serviços de saúde, sobretudo no CME,fazse necessário adotar medidas para controle de infecção nas redes de atendimento em saúde, no âmbito público e privado ${ }^{(11)}$.

\section{- MÉTODO}

Estudo de caso com aplicação de um questionário desenvolvido a partir das diretrizes recomendadas pela Sociedade Brasileira de Enfermeiros de Centro Cirúrgico - SOBECC ${ }^{(13)}$ e legislação da Agência Nacional de Vigilância Sanitária - ANVISA ${ }^{(11)}$ acerca dos processos de desinfecção e esterilização de materiais. Este estudo abordou as áreas do centro de material e esterilização, o fluxo dos produtos para saúde, tipos de invólucros e métodos de esterilização, testes de validação, registro das diferentes etapas do processo, além das condições de armazenamento e distribuição dos produtos reprocessados. 
Consideraram-se critérios de inclusão: ser profissional de enfermagem e estar atuando no processo de esterilização de produtos para saúde ou ser responsável pela área de esterilização de materiais, com no mínimo seis meses de atuação em ambulatórios de saúde do trabalhador vinculados a uma empresa do ramo alimentício, com sede no oeste do estado de Santa Catarina.

A unidade empresarial, com matriz no estado de Santa Catarina, possui filiais distribuídas nos estados de Santa Catarina $(n=11)$, Rio Grande do Sul $(n=3)$ e Mato Grosso do Sul $(n=1)$, totalizando 15 unidades ambulatoriais de saúde do trabalhador e todas possuem materiais reprocessáveis. Atualmente, cada unidade conta com um profissional de enfermagem responsável pelo processo de esterilização de materiais.

Participaram do estudotodos os profissionais de enfermagem atuantes na área de esterilização de produtos para saúde, em serviços ambulatoriais de saúde do trabalhador, representando as 15 unidades ambulatoriais, que respondem pelo processo de desinfecção e esterilização, sendo um profissional por unidade. Faz-se necessário esclarecer que algumas unidades dispunham de enfermeiro e outras de auxiliares e técnicos de enfermagem respondendo pelo processo de esterilização. Contudo, todos os ambulatórios de saúde do trabalhador em questãodesenvolvem ações de prevenção à saúde, assistência ambulatorial de pronto atendimento e cinco unidades (33,33\%) desenvolvem assistência odontológica aos trabalhadores.

A coleta de dados foi realizada com questionário, preenchido pelos próprios participantes na sede da empresa alimentícia, na presença de dois pesquisadores, os quais esclareceram dúvidas que emergiram no preenchimento do questionário, tais como a descrição do fluxo dos materiais odontomédico-hospitalares na estrutura física de cada unidade.

Os profissionais foram esclarecidos quanto ao objetivo da pesquisa e convidados a participar do estudo,preenchendo o Termo de Consentimento Livre e Esclarecido (TCLE) e informados sobre a aprovação da pesquisa pelo Comitê de Ética em Pesquisa da Universidade do Estado de Santa Catarina - UDESC, sob n³ 397.394/2013.

A pesquisa foi desenvolvida no período de junho a setembro de 2013, nas dependências da empresa. Logo após a coleta de dados, os profissionais participaram de uma capacitação. Vale salientar que o serviço viabilizou e custeou o transporte dos profissionais para que fosse possível a capacitação acerca do processo de desinfecção e esterilização de produtos para saúde, logo após a coleta de dados.

Os dados coletados foram tabulados e analisados por meio do Programa Microsoft Word Exce/®e Statistical Package for Social Science for Windows (SPSS), versão 18.0, por meio da estatística descritiva.

Ao término da coleta de dados, foi realizada capacitação a pedido da empresa, com du ração de quatro horas, oportunidade em que os pesquisadores abordaram diversas fases do processo esterilização, a saber: áreas que compõem o centro de material e esterilização; fluxo dos materiais durante o processamento; invólucros, métodos de desinfecção e esterilização; condições de armazenamento e distribuição dos produtos reprocessados; testes de validação; e registro das diferentes etapas deste processo.

Ao término do estudo, os resultados foram disponibilizados à enfermeira coordenadora dos serviços ambulatoriais de saúde do trabalhador da empresa para acompanhamento de mudanças acordadas coletivamente durante a capacitação.

\section{RESULTADOS}

Dos profissionais $(n=13)$ informaramque o enfermeiro é o responsável pelos processos de esterilização de materiais, contudo, em $n=14$ unidades, quem realiza as atividades é o técnico de enfermagem. No entanto, em um dos ambulatórios, o participante informou que quem realiza a esterilização é o auxiliar de consultório odontológico.

Os participantes $(n=15)$ consideram importante o papel da enfermagem nos processos de esterilização de materiais por auxiliar a minimizar ou eliminar os riscos de contaminação e, deste 
modo, oferecer serviço de qualidade aos usuários dos serviços de saúde.

Os participantes definiram desinfecção como sendo um processo realizado em materiais de procedimentos menos invasivos, sem contato com mucosas, caracterizando os instrumentais semicríticos. Quanto aos materiais que deveriam passar pelo processo de esterilização, os participantes sinalizaram os materiais invasivos, que entram em contato com mucosas, sangue e demais secreções, definindo como materiais críticos. Todos os participantes afirmaram que alguns instrumentais, de acordo com sua utilidade e tipo de material, devem passar inicialmente pelo processo de desinfecção e, posteriormente, pela esterilização.

A Tabela 1 apresenta que os materiais mais esterilizados nas unidades são os pacotes de curativo, materiais utilizados para a retirada de pontos, seguidos dos instrumentais cirúrgicos e material odontológico.

Na Tabela 2, observam-se os materiais que passam pelos processos de desinfecção. Os materiais que mais sofrem desinfecção são as ponteiras de otoscópio, os estetoscópios, termômetros e mobiliário, tais como macas, poltronas e bancadas. Todos os ambulatórios dispõem dos elementos descritos na Tabela 2. Entretanto, nem todos realizam o processo de desinfecção e quando o fazem, utilizam álcool $70 \%$.

Tabela 1 - Materiais que passam pelo processo de esterilização em ambulatórios de saúde do trabalhador. Chapecó, SC, 2013

\begin{tabular}{lcc} 
Materiais Esterilizados & $\mathbf{n}$ & $\mathbf{\%}$ \\
\hline Tecido & 2 & 13,33 \\
\hline Instrumental cirúrgico & 9 & 60 \\
\hline Pacote de curativo & 15 & 100 \\
\hline Retirada de ponto & 15 & 100 \\
\hline Material odontológico & 5 & 33,33 \\
\hline Outros* & 7 & 46,66
\end{tabular}

*Algodão, gase, chumaço, espéculo, abaixador de língua.
Tabela 2 - Materiais que passam pelo processo de desinfecção em ambulatórios de saúde do trabalhador. Chapecó, SC, 2013

\begin{tabular}{lcc} 
Materiais Desinfetados & $\mathbf{n}$ & $\mathbf{\%}$ \\
\hline Estetoscópio & 10 & 66,66 \\
\hline Pontas de Otoscópio & 15 & 100 \\
\hline Termômetro & 7 & 46,66 \\
\hline Cuba & 1 & 6,66 \\
\hline Mobiliário & 6 & 6,66
\end{tabular}

Quanto à exposição dos trabalhadores a riscos ocupacionais durante o processamento de materiais odonto-médico-hospitalares, todos responderam que há exposição do profissional aos riscos ocupacionais, sinalizando a exposição a riscos biológico, químico, físico. Dos participantes, 14 $(93,3 \%)$ reconheceram a existência de risco biológico e químico, $12(80 \%)$ a presença de risco físico no ambiente laboral e um (6,7\%) percebe o risco ergonômico na área de esterilização.

Os participantes enfatizam que o uso de EPIs protege o profissional. Todos os trabalhadores do CME fazem uso de no mínimo dois EPIs, entre eles, destacam-se as luvas, botas, jaleco (avental), máscara e óculos. Contudo, os trabalhadores participantes deste estudo informaram que os EPIs não são utilizados concomitantemente.

Em se tratando de fluxo de materiais no $\mathrm{CME}$, dois participantes apresentaram um fluxo unidirecional e 11 detalharam um fluxo incorreto, ou seja, que não segue em um único sentido entre as áreas que compõem o CME.Dois profissionais não responderam este questionamento e informaram, nesta questão, que não sabiam explicar o fluxo de materiais na CME por não ter um padrão definido na unidade. Em 13 unidades pesquisadas, o material entra e sai pela mesma porta.

Em todas as unidades acontece a pré-lavagem, lavagem e a secagem dos instrumentais, o empacotamento, a esterilização e o armazenamento dos materiais. Contudo, as unidades não possuem local específico para o processo de esterilização de materiais e, por este motivo, processam os materiais nas mesmas salas destinadas às consultas odontológicas e salas de procedimentos médicos. 
O armazenamento dos materiais reprocessados, em todas as unidades, acontece em armários ou gavetas. Tais situações, segundo os participantes, se dãopor terem baixo fluxo de atendimentos e que por ser uma unidade empresarial, há questões financeiras que interferem diretamente na conduta profissional perante o reprocessamento dos materiais. Apenas uma entre as 15 unidades de atendimento ambulatorial de saúde do trabalhador realiza registro dos processos de esterilização de materiais.

Os invólucros (embalagens) utilizados nas 15 unidades de atendimento são o papel grau cirúrgico. A Tabela 3 sinaliza os itens utilizados para a identificação do pacote pelos profissionais.

Quanto à identificação do pacote, 12 profissionais afirmam identificar com a data, sete com a hora, cinco identificam com o nome do profissional, umcolocao prazo de validade, quatro identificam com o nome do material e dois não identificam nada na embalagem a ser reprocessada. Deve-se levar em consideração que os participantes respondem mais do que um item de identificação do material.

Dos entrevistados, 11 referem realizar testes de controle do processo de esterilização, os demais afirmam não realizar nenhum teste para validar o processo de esterilização. Dos testes realizados, 10 realizam testes físicos com fita termorresistente e oito relatam fazer teste biológico com clean test. Dos que não realizam teste, relatam estar em período de aquisição do clean test. Quatro destes profissionais aguardavam a confirmação dos testes para a liberação do material para uso.

Nesta pesquisa,o método de esterilização utilizado pelas unidades pesquisadas foi calor úmido sob pressão (Autoclave). Considerando o método de esterilização empregado, os profissionais informaram uma grande diversidade quanto ao prazo de validade da esterilização, variando de sete dias a um ano conforme dados da Tabela 4. Além disso, quatro participantes relataram que não ter prazo de validade definido no ambulatório de sua atuação e um profissional diz que não controla o tempo de esterilização pela alta rotatividade dos materiais e por isso denominam "fluxo contínuo", quando os instrumentais não permanecem muito tempo em estoque. Faz-se necessário afirmar aqui que nenhum serviço pesquisado informou diferenciar o prazo de validade de acordo com o produto para saúde a ser esterilizado.

Tabela 3 - Rotulagem do material reprocessado em ambulatórios de saúde do trabalhador. Chapecó, SC, 2013

\begin{tabular}{lcc} 
Itens da Rotulagem/Identificação & $\mathbf{n}$ & $\mathbf{\%}$ \\
\hline Data de Esterilização & 12 & 80 \\
\hline Hora de Esterilização & 8 & 53,33 \\
\hline Assinatura do Profissional & 5 & 33,33 \\
\hline Prazo de Validade & 1 & 6,66 \\
\hline Nome do Material & 4 & 26,66 \\
\hline $\begin{array}{l}\text { Não Identifica o Material } \\
\text { Reprocessado }\end{array}$ & 2 & 13,33 \\
\end{tabular}

http://ojs.c3sl.ufpr.br/ojs2/index.php/cogitare/
Tabela 4 - Prazo de validade do processo de esterilização de materiais em ambulatórios de saúde do trabalhador. Chapecó, SC, 2013

\begin{tabular}{lcc}
\hline Validade do processo de esterilização & $\mathbf{n}$ & $\mathbf{\%}$ \\
\hline 7 dias & 4 & 26,66 \\
\hline 30 dias & 2 & 13,33 \\
\hline 60 dias & 1 & 6,66 \\
\hline 365 dias & 3 & 20 \\
\hline Conforme o uso & 1 & 6,66 \\
\hline Não tem prazo de validade definido & 4 & 26,66
\end{tabular}

Os participantes não diferenciam o prazo de validade de acordo com os produtos para saúde. 


\section{DISCUSSÃO}

O reprocessamento de materiais garante efetividade do processo de esterilização, possibilitando que o artigo esteja pronto para novamente ser utilizado ${ }^{(14)}$, sendo de extrema importância a presença de profissionais capacitados e qualificados, aprimorando sempre a execução dos processos a fim de contribuir no controle de infecções e assegurar uma assistência adequada e segura ao paciente ${ }^{(3)}$.

A pesquisa mostrou que o enfermeiro não realiza o reprocessamento dos materiais, mas é o responsável pelo processo. Esta informação é significativa, pois, ao atuar nos processos de esterilização de materiais, o enfermeiro exerce principalmente a gerência, a qual engloba diferentes funções, como planejamento, administração de recursos de materiais e de pessoal, supervisão dos serviços, dentre outros $^{(15)}$. Reafirma-se,assim, que o profissional que atua nos processos de esterilização de materiais geralmente é o auxiliar ou o técnico de enfermagem, contudo tais processos devem ser regidos e fiscalizados pelo enfermeiro ${ }^{(16)}$.

A enfermagem possui como essência a prática do cuidado, que reflete em diferentes ações, atuando de forma direta ou indireta com o paciente, ambas de grande relevância. O presente estudo evidenciou que o cuidado indireto realizado na CME demanda tempo de preparo e conhecimento para subsidiar a assistência direta com segurança, como a disposição de materiais livres de contaminação(15). O cuidado direto engloba toda e qualquer assistência prestada ao paciente, enquanto que o cuidado indireto abrange cuidados com o ambiente e processos para a atuação da enfermagem, como acontece na $\mathrm{CME}^{(15)}$.

A desinfecção é um processo baseado na imersão do material em um germicida químico ${ }^{(3)}$. AANVISA ${ }^{(11)}$ suspendeu os processos de esterilização por imersão em produtos químicos, em instrumentais cirúrgicos e produtos utilizados para procedimentos em geral.Todavia, para o processo de desinfecção, os produtos utilizados são o glutaraldeído $2 \%$, solução alcoólica de formaldeído $8 \%$, solução de formaldeído $10 \%$, clorexedine $2 \%$, polivilpirrolodoinaiodo (PVPI), álcool $70 \%{ }^{(3)}$. Contudo, neste estudo, o produto sinalizado para a desinfecção de materiais foi o álcool $70 \%$, não ficando os produtos para saúde em imersão, conforme sinalizado pela literatura(3)

Todos os serviços investigados neste estudo utilizam o calor úmido sob pressão (autoclave), considerado para o processo de esterilização de materiais o método mais utilizado, seguro e confiável(2), definido como esterilização a vapor saturado sob pressão, utilizado em instrumentais que não são sensíveis ao calor e ao vapor ${ }^{(2)}$.

O CME é considerado um ambiente complexo pela variedade de atividades realizadas e diversidade de materiais processados,o que favorece a exposição do trabalhador a possíveis riscos ocupacionais, visto que entra continuamente em contato com fluidos orgânicos, calor e substâncias químicas, em ambiente fechados e com rotinas exaustivas ${ }^{(17)}$. Embora nos resultados desta pesquisa tenha se identificado o reconhecimento dos fatores de riscos ocupacionais pelos profissionais, estudo afirma que os riscos químico, físico, biológico e ergonômico exigem cuidado especial, na prevenção e controle de acidentes ${ }^{(18)}$, sendo o risco físico o mais frequente, identificado pelo calor e falha no uso de EPI ${ }^{(17)}$.

Na estrutura física existem lacunas a serem sanadas, uma vez que o processo de esterilização se dá em sala de procedimentos médicos e odontológicos. No Brasil, a Resolução de Diretoria Colegiada -RDC $n^{\circ}$ 50, da ANVISA, regulamenta tal estrutura física e norteia a composição das áreas que compõem a $\mathrm{CME}^{(19)}$. Porém, não são todas as $\mathrm{CME}$ que seguem tais recomendações, muito provavelmente por motivos financeiros, estruturais e questões técnicas ${ }^{(20)}$.

A RDC no 15, de 15 de março de 2012 da ANVISA, prevê o uso de barreira técnica quando não há barreira física entre a área suja e área limpa, da mesma forma em que recomenda barreira técnica entre a área limpa e estéril. Além disso, a área de desinfecção deve ser restrita a esta atividade ${ }^{(11)}$.

Nesta pesquisa, os serviços ambulatoriais de saúde do trabalhadorestão em desconformidade com as recomendações daSociedade Brasileira de Enfermeiros de Centro Cirúrgico, Recuperação Anestésica e Centro de Material e Esterilização (SOBECC) e ANVISA, as quais defendem um fluxo unidirecional durante as etapas de reprocessamento, contemplando a limpeza/descontaminação, o acondicionamento e preparo dos materiais, a esterilização, o armazenamento e a distribuição dos 
produtos para saúde ${ }^{(21)}$. Estas etapasobjetivam evitar o contato de materiais sujos, limpos e esterilizados, como também que profissionais transitem ou atuem em determinadas áreas no mesmo momento ${ }^{(13)}$. $\mathrm{O}$ fluxo incorreto dos materiais pode resultar no cruzamento de materiais limpos e sujos, possibilitando a contaminação dos materiais já reprocessados ${ }^{(21)}$.

Os artigos recebidos no CME devem dar entrada pela área de recepção ou expurgo, onde ocorre o processo de lavagem ${ }^{(21)}$, encaminhados à área de preparo para inspeção, preparo e rotulagem de acordo com o processo de esterilização praticado. Para o armazenamento, o material processado deve ser estocado, observando-se as normas de distância mínima do piso, que é $20 \mathrm{~cm}$, do teto, $45 \mathrm{~cm}$, e da parede, $5 \mathrm{~cm}^{(13)}$. No entanto, os resultadosdesta pesquisadivergem dessas recomendações, apontando fragilidades que precisam de intervenção para a construção da melhoria do processo de esterilização.

Para o armazenamento, o local deve ser restrito para este fim, limpo, isento de poeira e seco, com temperaturas entre $18{ }^{\circ} \mathrm{C}$ a $22^{\circ} \mathrm{C}$ e umidade do ar de $35 \%$ a $60 \%$, sem janelas e portas abertas, tubulações expostas, e as prateleiras devem ser de aço ${ }^{(16)}$. Contrapondo os achados deste estudo, já que a área de esterilização não é exclusiva para este fim, não há controle de temperatura e umidade, nem guarda apropriada dos produtos para saúde já reprocessados.

As salas de guarda e armazenamento de materiais esterilizados, geralmente, são compartilhadas com a área de esterilização ${ }^{(20)}$. As autoclaves liberam, ao término do processo, vapor em grande quantidade e a estrutura física compromete a esterilização dos materiais, uma vez que altera os níveis de umidade e temperatura do ambiente ${ }^{(20)}$. Neste sentido, os resultados encontrados apontam o comprometimento do processo de esterilização, tanto pela maior liberação de umidade na área de guarda e distribuição de materiais que funciona no mesmo espaço físico da esterilização como pelo fluxo de pessoas, visto que o processo de esterilização acontece na sala de procedimento médico/odontológico.

Os resultados deste estudo reforçam o que aponta a literatura: que as etapas de registros dos processos de esterilização em unidades de saúde de pequeno porte podem não acontecer justamente por possuírem baixo fluxoe por realizarem o reprocessamento logo após a utilização dos instrumentais ${ }^{(21)}$. Estudo mostra queregistros na enfermagem, quando existem, mas incompletos, podem interferir no processo assistencial ${ }^{(22)}$. Os registros possibilitam a comunicação entre a equipe de saúde, promovem o cuidado com eficiência, qualidade e segurança, bem comoauxiliam no avanço da ciência da enfermagem através do desenvolvimento de novas experiências e conhecimentos ${ }^{(23)}$.

De acordo com a SOBECC, o papel grau cirúrgico é atualmente o invólucro mais indicado para os processos de esterilização de materiais em autoclaves ${ }^{(13)}$. Os invólucros possuem o objetivo de proteger o material depois do processo de esterilização, auxiliando na esterilidade do artigo até o momento do uso e possibilitando uma técnica asséptica e segura, e devem possibilitar uma identificação adequada dos artigos embalados ${ }^{(3)}$, minimizando os internamentos ou outros gastos nos serviços de saúde, provenientes de processos infecciosos decorrentes da fragilidade da assistência prestada ${ }^{(6)}$. Assim, os serviços investigados encontram-se adequados quanto à escolha do invólucro, conferindo segurança e estabilidade da esterilização até o momento de sua utilização.

A rotulagemdo produto para saúde é de extrema importância para identificar sua procedência e deve conter os seguintes dados: nome correto do artigo ou kit; número do controle de lote; data da esterilização; nome do funcionário que acondicionou o artigo; e, ainda, o tipo de processo de esterilização ${ }^{(3)}$, o que diverge dos resultados deste estudo, em que não há padronização dos elementos de rotulagem.

Aos serviços, orienta-se a cada unidade o estabelecimento de prazos de validade de produtos reprocessados. Contudo, é bom enfatizar que variáveis como temperatura e umidade do ar, condições das embalagens e o armazenamento são importantes para a qualidade deste material ${ }^{(3)}$ e seu controle precisa ser implementado em todos os ambulatórios investigados neste estudo.

Os produtos odonto-médico-hospitalaresnecessitam de controle rigoroso com finalidade de não comprometer a saúde do paciente com infecção hospitalar ${ }^{(2)}$. Dentre eles, o controle físico é realizado através da mensuração de parâmetros específicos durante a esterilização pela fiscalização do desempenho do esterilizador, tais como o manômetro de temperatura e pressão. Devem receber frequente manutenção, calibrados conforme a necessidade, não comprometendo a fidedignidade da 
leitura ${ }^{(3,5)}$.

Alguns esterilizadores de ultima geração possuem funcionamento com ciclos automáticos, fixos e controlados por um microprocessador e, ao término de cada ciclo, são obtidos registros impressos dos parâmetros do processo ${ }^{(3)}$. Embora serviços pesquisados disponham de equipamento esterilizador automatizado, pois os ciclos de esterilização são previamente programados, os equipamentos não emitem impressos com os dados sobre o processo de esterilização, o que exige do profissional o controle dos parâmetros físicos deste processo.

Os serviços investigados não realizam controles biológicos, os quais consistem em preparações padronizadas de esporos bacterianosque depois de passarem pelo processo de esterilização e terem acesso a um meio de cultura são incubadas em temperaturas de $37^{\circ} \mathrm{C}$ a $56^{\circ} \mathrm{C}$, com resultados efetivos e rápidos ${ }^{(5)}$. Neste processo, se houver proliferação e crescimento do micro-organismo, a cultura responde com uma alteração na coloração, o que sinaliza falha no processo de esterilização. Quando a cor se mantiver, o produto está esterilizado ${ }^{(3,5)}$.

Outro controle não realizado, segundo os participantes deste estudo,é o teste microbiológico, um indicador de leitura rápida nos testes de validação e de rotina da autoclave, de alta confiabilidade da leitura, segurança na liberação dos lotes e baixos riscos de infecção. A utilização é recomendada diariamente ou semanalmente em um único pacote no local mais frio, na primeira carga do dia ${ }^{(3)}$. Há uma carência deatualização profissional em unidades de serviços de saúde, resultando no desconhecimento de novas tecnologias do cuidado, as quais vêm se modificando constantemente ${ }^{(6)}$.

\section{- CONCLUSÕES}

Ao conhecer a prática dos profissionais que atuam em ambulatório de saúde do trabalhador, percebese um longo caminho a ser percorrido para melhorar as condições de desinfecção e esterilização dos materiais nestas unidades. Foram identificadasfragilidadestanto na estrutura física, que permita um fluxo unidirecional dos materiais reprocessados, quanto nos processos que permeiam a desinfecção e esterilização dos materiais odonto-médico-hospitalares, o que pode comprometer a segurança dos profissionais e dos usuários destes serviços.

As unidades de atendimento ambulatorial de saúde do trabalhador possuem fluxo contínuo de atendimento, requerendo uma reorganização dos processos, com vistas à implementação de área específica para o reprocessamento de materiais nas unidades pesquisadas. Ainda, percebe-se uma lacuna na manutenção preventiva de equipamentos nas unidades, contrapondo a legislação vigente no país.

Nesse sentido, orienta-se o desenvolvimento de protocolos de procedimentos por área do CMEa fim de possibilitar a uniformização dos processos e, consequentemente, a minimização dos custos e melhoria das condições sanitárias e de segurança do trabalhador.

Recomenda-se a implantação de testes físicos, químicos e biológicos para a validação do processo de esterilização, bem como o registro deste processo em todas as unidades, tornando possível o rastreamento dos materiais reprocessados. O adequado processo de desinfecção e esterilização e seu fiel registro, além de oferecer segurança aos trabalhadores, respaldam legalmente a empresa e os profissionais que atuam nestas áreas.

Este estudo revela a necessidade daeducaçãocontinuada em serviçovisando a acompanhar o desenvolvimento de novas tecnologias do cuidado e implementar estratégias para as boas práticas no que tange ao processo de desinfecção e esterilização. Ainda, os resultados evidenciam a carência de reorganização estrutural e procedimental acerca da desinfecção e esterilização de produtos para saúde a fim de responder minimamente a legislação brasileira vigente.

Conforme a Norma Regulamentadora - NR 32/2002, que dispõe sobre a segurança e saúde no trabalho em serviços de saúde, torna-se necessário praticar educação continuada, requisito fundamental para capacitar os profissionais da área da saúde que realizam o reprocessamento de materiais, assim como o desenvolvimento de novos estudos que mensurem o efeito das capacitações em serviços de saúde. 
No entanto, a responsabilidade técnica do processo de esterilização deve ser assumida por profissional habilitado para tal, com vistas à melhoria da qualidade dos serviços de saúde dispensados aos trabalhadores em ambulatórios empresariais.

\section{- REFERÊNCIAS}

1. Potter PA, Perry AG. Fundamentos de enfermagem. 5. ed. Rio de Janeiro: Guanabara Koogan; 2004.

2. Mozachi N, Souza VHS. O hospital: manual do ambiente hospitalar. 3. ed. Curitiba: Ed. Curitiba; 2009.

3. Possari JF. Centro de material e esterilização: planejamento, organização e gestão. 4. ed. São Paulo: látria; 2010.

4. Paurosi DR, Ascari RA, da Silva OM, Ascari TM. Diretrizes operacionais para uma central de Material e esterilização odontológica: Uma proposta da enfermagem. Revista UNINGÁ Review. Maringá. 2014; 17(2) [acesso em 08 jan 2015]. Disponível: http://www.mastereditora.com.br/periodico/20140129_171733.pdf

5. Berlet LJ, Ascari RA, da Silva OM, Trindade LL, Krauzer IM, Jacoby AM.Factors that influence the quality of the sterilisation process. J Nurs UFPE on line. 2014: 8(7) [acesso em 07 jan 2015]. Disponível: http://www.revista.ufpe. br/revistaenfermagem/index.php/revista/article/view/5780/pdf_5484

6. Maldaner C, Berlet LJ, Ascari RA, Klein ML, Savian BA, da Silva OM. Invólucros para Esterilização de Materiais odonto-médico-hospitalares.Rev Saúde Pub Santa Catarina. 2013; 6(3) [acesso em 02 fev de 2015]. Disponível: http://esp.saude.sc.gov.br/sistemas/revista/index.php/inicio/article/viewFile/180/223

7. Ouriques CM, Machado MÉ. Nursing in the process of sterilization of materials. Texto contexto - enferm. 2013; 22(3) [acesso em 20 jan 2015]. Disponível: http://dx.doi.org/10.1590/S0104-07072013000300016

8. Ascari RA, Vidori J, Moretti CA, Perin EMF, da Silva OM, Buss E. O processo de esterilização de materiais em Serviços de Saúde: uma revisão integrativa.Braz. J. Surg. Clin. Res., 2013; 4(2) [acesso em 22 dez de 2014]. Disponível: http://www.mastereditora.com.br/periodico/20130831_181149.pdf

9. Bianchi EC, da Silva EJ, Cezar FAG, Aguiar PR, Bianchi ARR, Freitas CA, Riehl H. Aspectos microscópicos da influência dos processos de esterilização em pontas diamantadas.Mat Res. 2003;6(2) [acesso em 14 nov 2014]. Disponível: http://dx.doi.org/10.1590/S1516-14392003000200015

10. Ministério do Trabalho e Emprego(BR). Norma Regulamentadora № 32 - Segurança e Saúde no Trabalho em Estabelecimentos de Saúde. Ministério do Trabalho e Emprego, 2011. [acesso em 14 nov 2014]. Disponível: http:// portal.mte.gov.br/legislacao/normas-regulamentadoras-1.htm

11. Ministério da Saúde (BR). Agência Nacional de Vigilância Sanitária - ANVISA. RDC N. 15 de 15 de março de 2012 que dispõe sobre requisitos de boas práticas para o processamento de produtos para saúde e dá outras providências [acesso em 22 ago 2013]. Disponível: http://portal.anvisa.gov.br/wps/wcm/connect/7599770043e68 4468b198f45f4f7d4e4/rdc0015_15_03_2012.pdf?MOD=AJPERES

12. Ascari RA. Retrospectiva das políticas de saúde do trabalhador no brasil: avanços e desafios do sistema único de saúde - SUS. Acta JUS - Periódico de Direito. 2014; 4(1) [acesso em 20 abr 2015. Disponível: http://www. mastereditora.com.br/periodico/20150411_124642.pdf

13. Sociedade Brasileira de Enfermeiros de Centro Cirúrgico, Recuperação Anestésica e Centro de Material e Esterilização (SOBECC). Manual de práticas recomendadas da SOBECC. 6ª ed. São Paulo; 2013.

14. Psaltikidis EM, Graziano KU, Frezatti F. Cálculo dos custos do reprocessamento de pinças de uso único utilizadas em cirurgia video-assistida. RevEscEnferm USP. 2006; 40(2). Disponível: http://dx.doi.org/10.1590/ S0080-62342006000200012

15. Bartolomei SRT, Lacerda RA.Trabalho do enfermeiro no centro de material e seu lugar no processo de cuidar pela enfermagem.RevEscEnferm USP. 2006; 40(3) [acesso em 20 nov 2014].Disponível: http://dx.doi.org/10.1590/ S0080-62342006000300014 
16. Moura MLPA. Enfermagem em centro de material e esterilização. $10^{\circ}$ ed. São Paulo: SENAC; 1994.

17. Espindola MCG, Fontana RT. Riscos ocupacionais e mecanismos de autocuidado do trabalhador de um centro de material e esterilização. Rev. Gaúcha Enferm. 2012; 33(1) [acesso em 16 fev 2015]. Disponível: http://dx.doi. org/10.1590/S1983-14472012000100016

18. Sulbacher E, Fontana RT. Concepções da equipe de enfermagem sobre a exposição a riscos físicos e químicos no ambiente hospitalar. RevBrasEnferm. 2013; 66(1) [acesso em 18 nov de 2014]. Disponível: http://dx.doi. org/10.1590/S0034-71672013000100004

19. Ministério da saúde(BR). Agência Nacional de Vigilância Sanitária - ANVISA. RDC Nº 50, de 21 de fevereiro de 2002 que aprova o Regulamento Técnico destinado ao planejamento, programação, elaboração, avaliação e aprovação de projetos físicos de estabelecimentos assistenciais de saúde. ANVISA, 2002. [acesso em 17 out 2014]. Disponível: http://portal.anvisa.gov.br/wps/wcm/connect/ca36b200474597459fc8df3fbc4c6735/RDC+N\%C2\%BA .+50,+DE+21+DE+FEVEREIRO+DE+2002.pdf?MOD=AJPERES

20. Bruna CQM, Graziano KU. Temperature and humidity in the storage area of sterile materials: a literature review. Rev. esc. enferm. USP. 2012; 46(5) [acesso em 22 nov 2014]. Disponível: http://dx.doi.org/10.1590/S008062342012000500025

21. Ascari RA, Silva OM, Azevedo Junior L, Berlet LJ, Maldaner C, Mai S. Fluxo de materiais odonto-médicohospitalares durante o seu reprocessamento em unidades básicas de saúde. RevUdesc em Ação. 2012; 6(1) [acesso em 20 dez 2014]. Disponível: http://www.revistas.udesc.br/index.php/udescemacao/article/viewFile/2486/ pdf_102

22. Marques PA, Melo ECP. The working process of a neonatal intensive care unit. Rev. esc. enferm. USP. 2011; 45(2) [acesso em 18 dez 2014]. Disponível: http://dx.doi.org/10.1590/S0080-62342011000200011

23. Barra DCC, Dal Casso GTM. Padrões de dados, terminologias e sistemas de classificação para o cuidado em saúde e enfermagem.RevBrasEnferm, 2011; 64(6) [acesso em 15 fev 2015]. Disponível: http://dx.doi.org/10.1590/ S0034-71672011000600023 